\title{
Benefits of the Tracers Test Technique in improving The Performance of Group Wells
}

Dike Fitriansyah Putra1 ${ }^{*}$, Mursyidah Umar ${ }^{1}$, Lazuardhy V Futur ${ }^{1}$, Aznil Arif Rahman ${ }^{1}$

${ }^{1}$ Department of Petroleum Engineering, Faculty of Engineering, Universitas Islam Riau, Jl. Kaharuddin Nasution No. 113, Pekanbaru, Riau Province, Indonesia - 28284

*Corresponding Author: dikefp@eng.uir.ac.id

\begin{tabular}{|c|c|}
\hline Article History: & Abstract \\
\hline $\begin{array}{l}\text { Received: November 7, } 2019 \\
\text { Receive in Revised Form: February 22, } 2021 \\
\text { Accepted: March 8, } 2021\end{array}$ & \multirow{3}{*}{$\begin{array}{l}\text { This study aims to determine the benefits of the interwell tracer test } \\
\text { technique in improving the streamline simulation on the existing } \\
\text { array's re-look. It also analyses the best scheme for the injection spot } \\
\text { to enhance oil recovery. This study's subject parameters are limited } \\
\text { to the tracer's breakthrough time, produced concentration, } \\
\text { cumulative production, and pathline movement. The results showed } \\
\text { that previous studies distinguished the correlation between injectors } \\
\text { and producers with the development of a new pathline that conveys } \\
\text { a scheme of water-flood for the application. Furthermore, several } \\
\text { developments of water-flood schemes have been executed for better } \\
\text { oil recovery in the mature fields worldwide. The vigorous simulation } \\
\text { model is an effort to imitate the actual field capable of enhancing the } \\
\text { character's understanding and helping the waterflood to rinse the oil } \\
\text { trap or the unswept pocket. Unlike a Cartesian model, the streamline } \\
\text { conveys an enhanced portrait of the transmissibility reservoir in } \\
\text { terms of pressure-driven. The streamline model suggests the } \\
\text { injector's preferred position to unlock any unswept oil in the } \\
\text { formation and minimize the water path conflict, which leads to over } \\
\text { Injection in some regions. The expected outcome is the ultimate oil } \\
\text { increment with the original technique associated with re-patterning } \\
\text { the wells appropriately to gain residual oil saturation in the virgin } \\
\text { alleyway. }\end{array}$} \\
\hline Keywords: & \\
\hline $\begin{array}{l}\text { Tracer, Streamline, Water-flood, Pattern } \\
\text { Design. }\end{array}$ & \\
\hline
\end{tabular}

\section{INTRODUCTION}

The waterflood scheme is the most appropriate technique to advance oil recovery, irrespective of the reservoir's variant characteristics. According to Alhuthali et al. (2007), the reservoir's negative physical appearances are unfavorable with the presence of extraordinary permeability streaks, high ratio of net to gross, permeability contrast, and heterogeneity formation of substances. Thrasher et al. (2016) stated that the high reservoir heterogeneity generally restricts the execution of water-flood. This process is known as the conformance problem, and it affects the poor volumetric sweep efficiency of a conventional water flood (Temizel et al., 2018).

Two types of well sites are famous in waterflooding, namely central flooding, which uses repeated patterns throughout the field, and the peripheral where the injectors are grouped (Asadollahi, 2012).

The accomplishment of the water-flood scheme is determined by the steadiness and consistency of transmissibility in the formations and the contact interaction between the reservoir fluids and the injection liquids (Mursyidah et al., 2020). Melo \& Almeida (2017) stated that tracer surveillance needs to be carried out before the water-flood implementation process to fully determine the communication between injectors and producers in one region or segment. One of the prodigious tools used to assess the stream's numerous characteristics possessions in a system is the Residence Time Distribution (RTD) analysis (Huseby et al., 2014). Another technique is utilizing the Time of Flight (TOF) to measure the properties of grid block in terms of flow pathline. 
The tracer objective in the fossil industry is to evaluate the interwell correspondence among wells and their bond to form heterogeneity (Huseby et al., 2015). The tracer assessment provides the variation of the flooding streamline within the heterogeneity formation. This pathline is geologically indistinguishable or opposite under the natural fracturing, fracture systems, fault frontier, great permeability vein, high permeability thief zones, or stream-blockade (Samaniego et al., 2005). Various types of tracer fluid have been added into the injection influx to monitor the streamline as a fluid carrier (Du \& Guan, 2005). The pathline is determined as favored conduits used to move the fluid from a socket in the reservoir (producers) to others (injectors). Furthermore, various observations have been made to monitor the breakthrough time and the fluid stream of producers.

\section{METHODOLOGY}

\section{Streamline Practices}

Streamlines curves are based on the instantaneous fluid and the vicinity oblique to the velocity direction (Ruan et al., 2002). Figure 1 shows streamlines traced from a snapshot of the velocity at a time of interest under a time-varying velocity. A streamline is the neutral tracer particle arc capable of moving over interstellar within a specific time. It is also dependent on the magnitude and direction of the velocity. Meanwhile, for a sturdy velocity, the pathline, and the streamline define the same path (Martha et al., 2000).

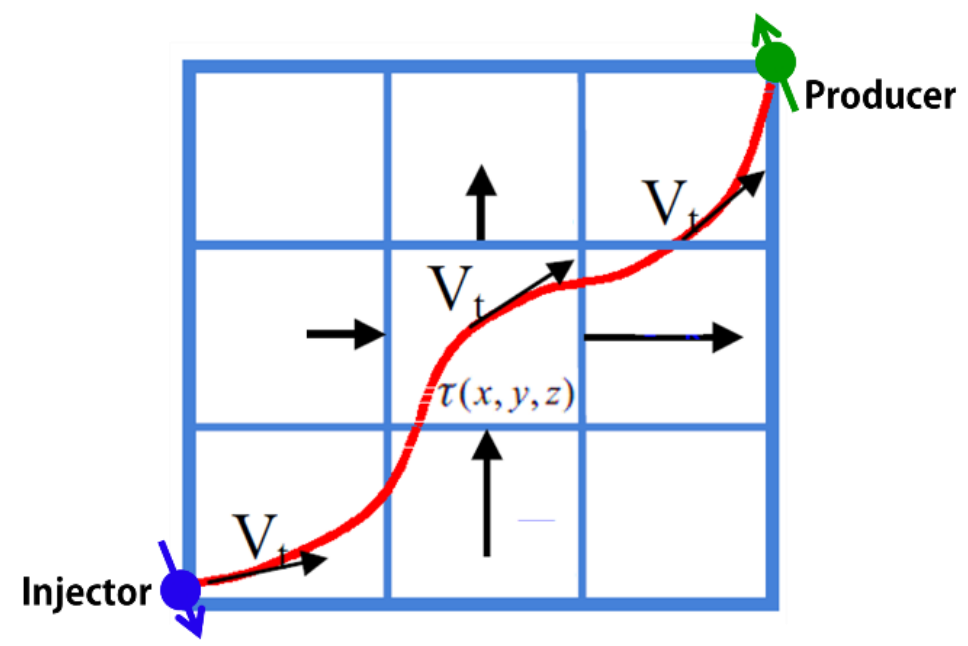

Figure 1. Illustration of the streaming Time Of Flight (TOF)

The TOF (Time-of-Flight) is the sum of the residence time (1)(Park et al., 2006)

$$
\tau=\sum_{i}^{n} \Delta f_{i}
$$

$\mathrm{T}$ is TOF [T], $\mathrm{N}$ denotes the total number of blocks that a streamline passes, while $\Delta \mathrm{f}$ is the residence time of streamline $\mathrm{i}$. The forward tracing from the injector flows until inward-bound the producer.

\section{Tracer Test Technique}

The tracer technologies have proven to be an efficient tool in examining the formation flow performance and properties responsible for driving the gas and water displacement practices in the petroleum industry (Guan \& Du, 2004).

The interwell tracer is a test that uses one or several injecting tracers in the injectors. Its chemical is associated with the transporter fluid, such as flooding in water and gas. After a certain period, the fluid samples are collected in the producer for identifying the tracer chemical breakthrough (Sanni et al., 2015).

The tracer trial investigates some evidence on the pathline array during the formation process. This information helps in reducing the uncertainty of the current track by delivering a conclusive, dependable, and promptly noticeable pathline capable of decreasing the uncertainty of reservoir flow patterns and their continuity. Hence, the information reservoir continuity needs to be obtained based on the amount of each tracer produced (Cuauro et al., 2014). 
The tracer arrangement is an essential phase for a successful field trial; therefore, an incomplete proposal tends to have a misleading result. Some points need to be revealed in the interwell scenario, as follows:

- $\quad$ Explicitly declaring the purpose of the tests (Viig et al., 2013)

- $\quad$ The applicable area selection (Sagen et al., 1996)

- The right tracer and its concentration (Anisimov, 2009).

The wells selected for the successful monitoring and evaluation of the tracer execution is a critical decision to be made. Hypothetically, all active wells in the vicinity of the tracer injectors need to be monitored. However, there are possibilities that the selected wells will not function due to the limited budget cost of the project, therefore only a few numbers of producers are observed. Hence, the producers are appraised based on up-to-date data with several scenarios arranged to mitigate the failure.

The required amount of tracer material (Ws) is estimated by Equation (2). The Ms and Ma denote the molecular weight of the tracer compound and active tracer material, $n$ is the number of moles of active material per mole, and MDL is the minimum detectable limit, expressed as a weight of active tracer per unit volume of produced water (Zemel, 1995).

$$
\boldsymbol{W s}=\boldsymbol{n} *\left(\frac{M s}{M a}\right) *(M D L) * V d
$$

A tracer's success does not mean its analysis in a specific produced water sample has equal success with different conformation.

In the actual field, the tracer test's success depends on the amount covered by the tracer fluid recovered in the production wells. Hao et al. (2011) stated that $40 \%$ volume tracer recovery had been considered a success within a closed radius of $700 \mathrm{~m}$. Therefore, in conclusion, both wells have an inter-connection.

A high-pitched goal is essential to a successful interwell tracer. The first target of the interwell test is to scrutinize the property's quality of formation. This is followed by the process of reducing the uncertainty of interconnection among injectors and producers. The third is to define the flow pattern of the fluids in the reservoir.

The well selection is based on the tracer path line's hypothesis with its chemical used to liquify the fluid carrier along with a dependable velocity. Although the tracer components do not react to the minerals on the reservoir's grain, the volume accumulation does not need to be less than the object reading in each layer. The tracer fraction needs to be discovered and analyzed in part per million concentrations. Economically, it needs to be cost-effective, safe for the environment, and meet conservation protocols, either locally or globally.

It is mandatory to seek tracer substances that are able to deal with all subsurface elements. However, it is also difficult to determine a tracer material that is unable to react, engrossed, and disintegrated by any natural elements that presences in the subsurface under reservoir conditions, such as high pressure and temperature. Therefore, before the pilot test, a laboratory study needs to be performed thoroughly to screen and investigate all candidate tracers, irrespective of the associated difficulty in conducting these tests.

\section{RESULTS}

\section{Gullfaks Field (Study Case)}

The Gullfaks field was awarded in mid-1978 to Statoil and started operation in 1981. It comprises platforms A, B, and C, which were established in late 1986, early 1988, and November 1989 . The main field's STOOIP is $3.767 \mathrm{MMBO}$, the production at the end of 2007 was $2.103 \mathrm{MMBO}$, which is approximately $56 \%$ oil recovery factor (Flo et al., 2012). As of the end of 2011, oil production was 2.209 MMBO, thereby making the recovery factor $58.65 \%$. The three platforms' capacity is approximately $630 \mathrm{MBOD}$, with the Gullfaks field containing up to 100 wells, including injectors of water and gas to maintain the pressure in the reservoir (Nordas, 2000).

The Cook Formations, and the Early Jurassic Statfjord, and the Middle Jurassic Brent Group approximately comprise oil up to 7.5 percent, 16.5 percent, and 75 percent, respectively (Bale et al., 2008). Brent group has five formations consisting of Broom, Rannoch, and Etive (Lower B1), Ness, and Tarbert (Upper B1).

The Gullfaks field is sited in block 34/10 on the Norwegian continental shelf, which is underlying in the middle region of the East Shetland Basin. This basin comprises the structural basics of Tampen Spur, Viking Graben, and Sogs Graben (Putra, 2007). 
The Gullfaks field is a complex reservoir, and it embraces three regions, the first section is a Horst area in the east. The second is 'Domino Area' with rotated fault blocks in the west. Between these two sections is a complex 'Adaptation Zone,' categorized by folding structures with a south-north fault that split up the field up to $984 \mathrm{ft}$. In the western part, the slope of the fault is typically around 28 degrees downward to the east, whereas in the eastern it is 60-65 degrees towards the west (Hesjedal \& Eltvik, 2008).

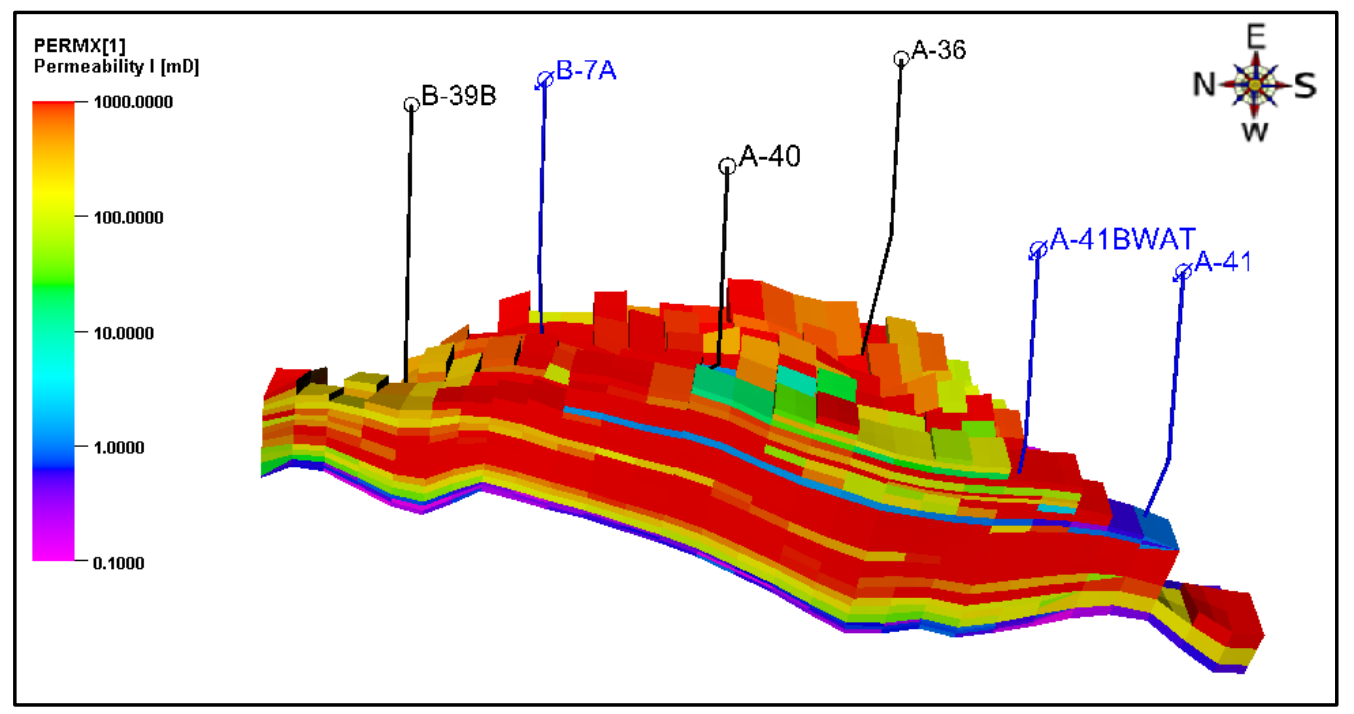

Figure 2. Reservoir Permeability Distribution on Gullfaks Field

Figure 2 shows the permeability distribution of the Gullfaks field with initial reservoirs of 4,496 psi at datum depth of 6,069 ft below mean sea level. The temperature reservoir is 165.2 degrees $F$. The petroleum system is undersaturated condition, with a saturation pressure of approximately 3,553 psi, based on the location and depth of formation. The gas oil ratio is within 90 and $180 \mathrm{ft}^{3} / \mathrm{ft}^{3}$, with stock tank oil gravity around 53.69 $\mathrm{lb} / \mathrm{ft} 3$ (Hesjedal \& Eltvik, 2008). According to Talukdar \& Instefjord (2008), the oil gravity is between 32 $36{ }^{\circ} \mathrm{API}$, and the initial GOR in Brent is $100 \mathrm{ft}^{3} / \mathrm{ft}^{3}$.

\section{Streamline Tracer Test}

The streamline tracer test is used to determine the interwell corresponding between injectors and producers. The analysis is executed on three injectors, namely A-41BWAT, A-41, and B-7A, with the volume of chemical tracer injected to $2 \mathrm{~m}^{3}$ or 12.58 barrels on September 3, 2006. The rise of tracer in the producer is considered once the concentration reaches above $1 \mathrm{ppm}$. Meanwhile, the interwell connection is recommended, assuming the percentage of tracer volume collected is above 40\% (Cheng et al., 2011). Figure 3 shows WN1 tracer arose in wells A-36 on May 1, 2007 (RTD 242 days within distance 534m) and reached its peak on June 5,2008 , with an average concentration of 5.3 ppm. WN1 appeared on November 1, 2008 (RTD 549 days within distance 956m) and reach the peak in wells A-40 on November 1, 2010, with an average concentration of $4.2 \mathrm{ppm}$. Meanwhile, the WN1 materialized in wells B-39B on March 1, 2010 (RTD 1,276 days within distance $1,720 \mathrm{~m}$ ) and reached the peak on July 1, 2013, with an average concentration of $3.4 \mathrm{ppm}$.

Figure 4 shows the cumulative WN1 produced in wells A-36, A-40 AND B39B are as much as 34\%, 22\%, and up to $9 \%$ at the end of the simulation. According to Hao et al. (2021), all the results are below $40 \%$ due to the substantial difference in rock formation between the Minas and Gullfaks fields, which comprises homogeneous sandstone with a fault and fracture network. The layer sands are like a layer cake, therefore, the flow pathline easily reaches the producers without any significant interruption. More than $40 \%$ of the chemical tracer attains the producer within a 700m space. Meanwhile, the Gullfaks field significantly distinguishes the formation quality between nearby layers. The dense fault pattern dictates wide well spacing in some areas and close distance in others, which is often joined with poor internal reservoir quality into producers (Hesjedal \& Eltvik, 2008). Even though the distance between injector A-41BWAT and producer A-36 is less than $700 \mathrm{~m}$, at exactly $534 \mathrm{~m}$, the TOF of tracer takes 242 days to achieve $34 \%$ volume. For more than $1000 \mathrm{~m}$ distance, such as injector A-41BWAT and producer B-39B, the TOF reaches up to 1,276 days and recovers volume by $9 \%$. Therefore, the author considers those results to represent good inter-connection between injectors and producers. Meanwhile, the tracer volume recovered less than $10 \%$ is considered poor connectivity. 


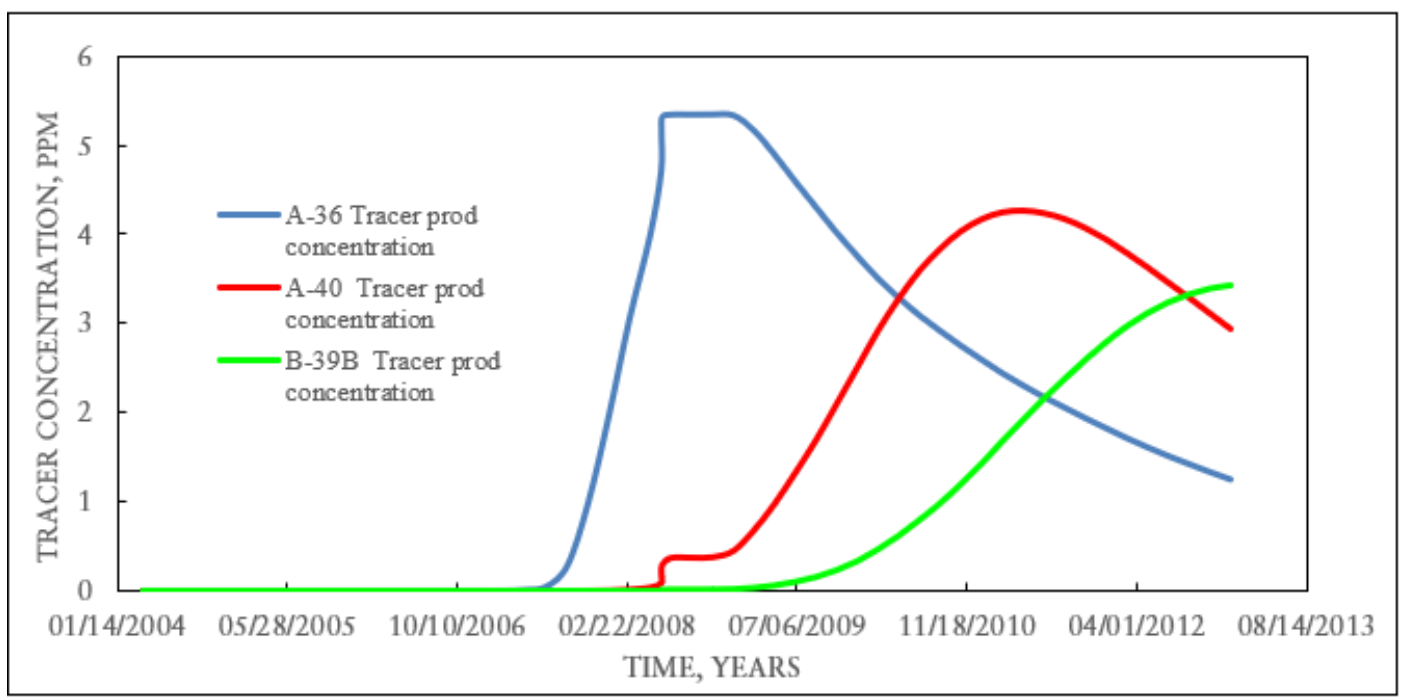

Figure 3. Tracer concentration against time (WN1)

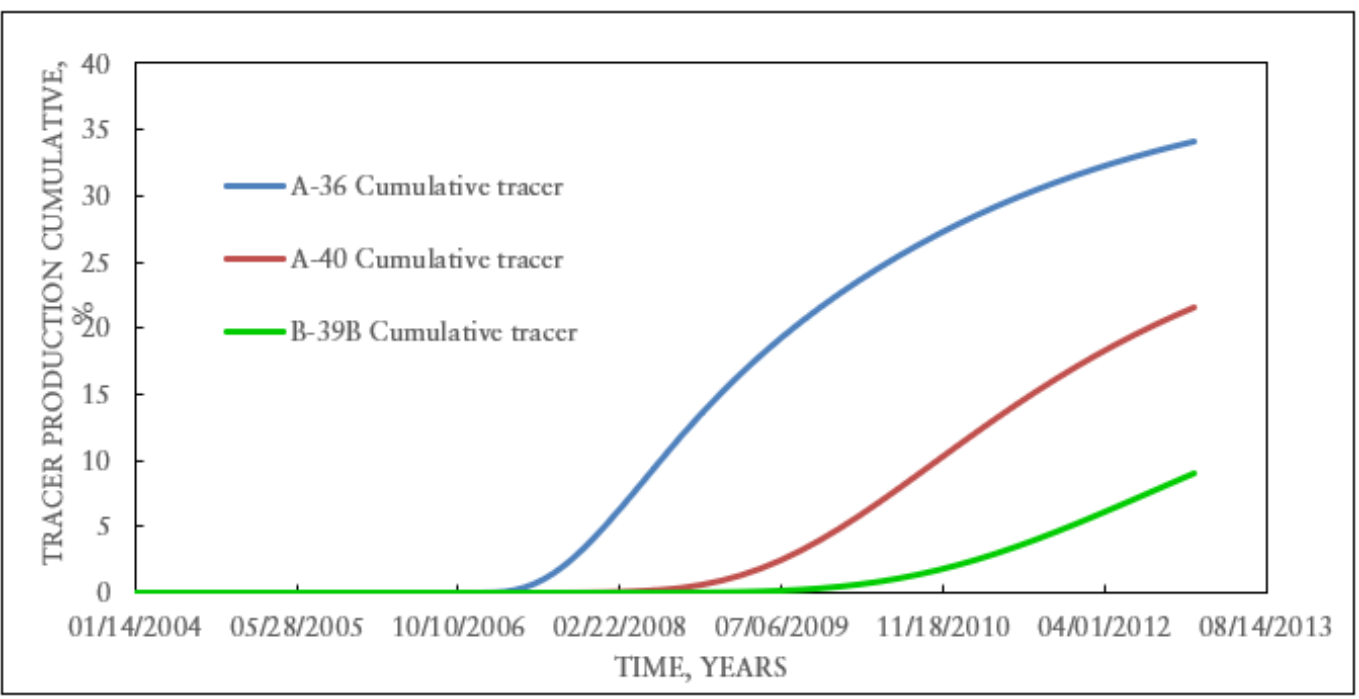

Figure 4. Tracer Production Cumulative against Time (WN1)(Mursyidah et al., 2020)

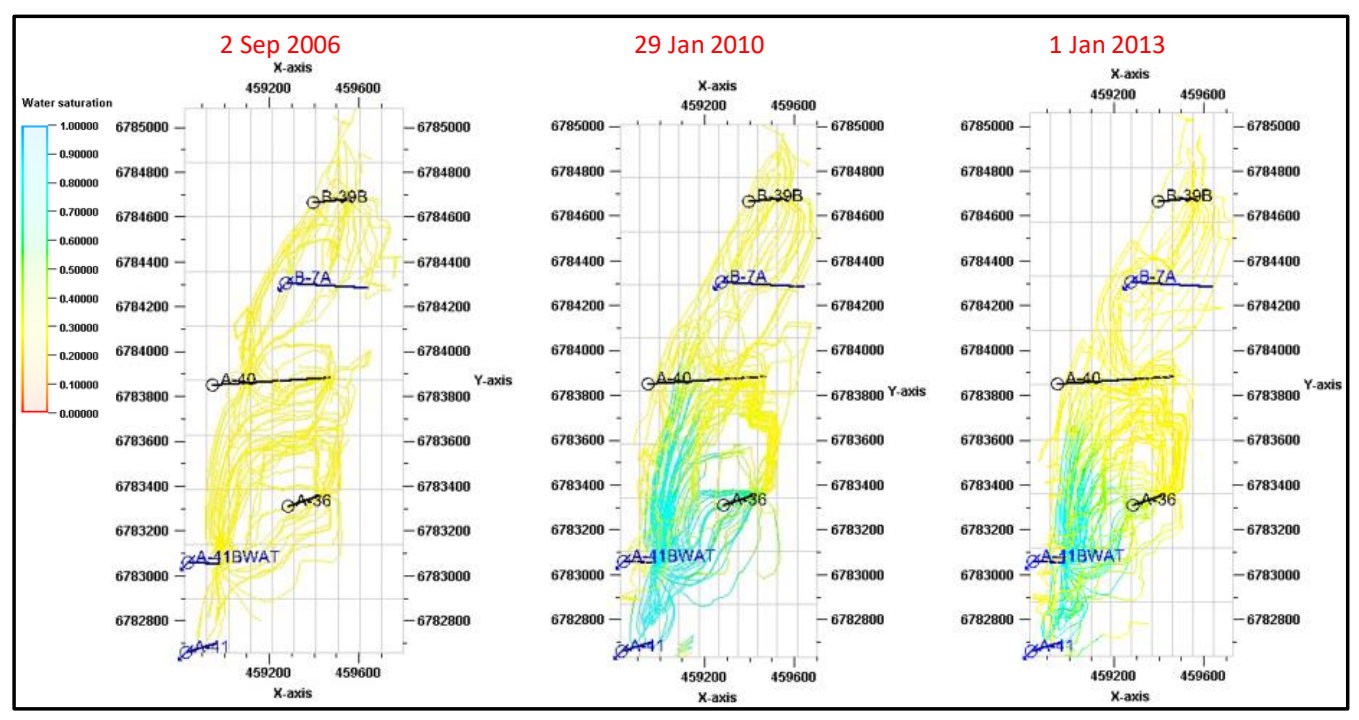

Figure 5. The streamline of water injectors A-41BWAT 
Figure 5 shows the streamline of water injectors A-41BWAT from the wells on September 1, 2006, three days after Injection. On January 1, 2010, the tracer reached A-36 and started to close producers A-40. On January 1, 2013, the tracer passed producer A-40 and partially rose in B-7A. Principally, this streamlined simulation shows that A-41BWAT has satisfactory communication to all producers, and the finest link is A36 due to the closed distance between them.

Table 1 shows the result of the tracer tests in A-41BWAT, A-41, and B-7A, including the time of flight (TOF), peak concentration identified, cumulative tracer volume collected as well as the distance between injector and producers.

Table 1. Tracer simulation conclusion of three injectors

\begin{tabular}{|c|c|c|c|c|c|c|c|c|c|c|}
\hline \multirow[t]{2}{*}{ TRACER } & \multirow[t]{2}{*}{$\begin{array}{l}\text { Injector } \\
\text { Wells }\end{array}$} & \multicolumn{3}{|c|}{ A-36 } & \multicolumn{3}{|c|}{$A-40$} & \multicolumn{3}{|c|}{ B-39B } \\
\hline & & $\begin{array}{l}\text { DATE } \\
\text { (TOF) }\end{array}$ & $\begin{array}{l}\text { CONC, } \\
\text { ppm }\end{array}$ & $\begin{array}{c}\text { CUM, \% } \\
\text { (Distance) }\end{array}$ & $\begin{array}{l}\text { DATE } \\
\text { (TOF) }\end{array}$ & $\begin{array}{c}\text { CONC, } \\
\text { ppm }\end{array}$ & $\begin{array}{c}\text { CUM,\% } \\
\text { (Distance) }\end{array}$ & $\begin{array}{l}\text { DATE } \\
\text { (TOF) }\end{array}$ & $\begin{array}{c}\text { CONC, } \\
\text { ppm }\end{array}$ & $\begin{array}{c}\text { CUM, \% } \\
\text { (Distance) }\end{array}$ \\
\hline WN1 & $\begin{array}{c}\text { A-41 } \\
\text { BWAT }\end{array}$ & $\begin{array}{c}01 / 05 / \\
07 \\
(252 d)\end{array}$ & 5.3 & $\begin{array}{c}34 \\
(543 \mathrm{~m})\end{array}$ & $\begin{array}{c}01 / 11 / \\
08 \\
(549 d)\end{array}$ & 4.2 & $\begin{array}{c}22 \\
(951 \mathrm{~m})\end{array}$ & $\begin{array}{c}01 / 03 / \\
10 \\
(1276 \mathrm{~d} \\
)\end{array}$ & 3.4 & $\begin{array}{c}9 \\
(1720 \mathrm{~m})\end{array}$ \\
\hline WN2 & A-41 & $\begin{array}{c}01 / 09 / \\
07 \\
(365 d)\end{array}$ & 6.2 & $\begin{array}{c}37 \\
(>543 \mathrm{~m})\end{array}$ & $\begin{array}{c}01 / 11 / \\
08 \\
(791 d)\end{array}$ & 4.5 & $\begin{array}{c}22 \\
(>951 \mathrm{~m})\end{array}$ & $\begin{array}{c}01 / 11 / \\
12 \\
(2251 d \\
)\end{array}$ & 3.5 & $\begin{array}{c}8 \\
(>1720 m\end{array}$ \\
\hline WN3 & B-7A & $\begin{array}{c}01 / 03 / \\
10 \\
(991 d)\end{array}$ & 2.5 & $\begin{array}{c}17 \\
(951 \mathrm{~m})\end{array}$ & $\begin{array}{c}01 / 09 / \\
06 \\
(61 d)\end{array}$ & 21.3 & $\begin{array}{c}30 \\
(437 \mathrm{~m})\end{array}$ & $\begin{array}{c}01 / 12 / \\
06 \\
(181 d)\end{array}$ & 15 & $\begin{array}{c}24 \\
(414 \mathrm{~m})\end{array}$ \\
\hline
\end{tabular}

The table shows that the volume cumulative of tracer produced from the three producers is within the range of $8 \%-37 \%$ of the total volume injected. Only two pairs have the tracer volume recovered less than $10 \%$, with the majority above $10 \%$. The simulation run determines the inter-connection between the three injectors with the three producers. The majority have good inter-connectivity, as opposed to a few.

\section{Re-arrangement Injection Spots}

From those tracer outcomes, the authors designed 6 cases for simulation, with either single or a couple of injectors. Therefore, the optimum scenario within the same period of production needs to be selected based on the running result. The cumulative oil is the parameter used to choose the top preference. The scenarios simulate randomly on the water-flood array, as shown in Table 2. The sum fluid inserted into injectors is $5250 \mathrm{bbl} /$ day at the pressure of Injection $3000 \mathrm{psi}$.

Table 2. Scenario of injection designs

\begin{tabular}{ccccccc}
\hline Scenario & \multicolumn{3}{c}{ Injector } & \multicolumn{3}{c}{ Producers } \\
\hline 1 & & A-41BWAT & & A-39B & A-36 & A-40 \\
2 & & A-41BWAT & A-41 & A-39B & A-36 & A-40 \\
3 & B-7A & A-41BWAT & & A-39B & A-36 & A-40 \\
4 & B-7A & A-41BWAT & A-41 & A-39B & A-36 & A-40 \\
5 & B-7A & & & A-39B & A-36 & A-40 \\
6 & & & A-41 & A-39B & A-36 & A-40 \\
\hline
\end{tabular}

Another unique finding in the model during a pair or triple injections is the intersect flow of 2,3 , and 4 scenarios. This intersection flow creates over injection volume for a certain region, leading to excess water in the subject grids. All simulation scenarios are shown in Table 3. 
Table 3. Result and summary

\begin{tabular}{ccccc}
\hline Scenario & $\begin{array}{c}\text { Oil Cumulative, } \\
\text { Barrels }\end{array}$ & $\begin{array}{c}\text { First Oil Prod rate, } \\
\text { Barrels/Day }\end{array}$ & Intersect time, Date & $\begin{array}{c}\text { First intersect time, } \\
\text { Month }\end{array}$ \\
\hline 1 & $1,294,307.00$ & $1,271.79$ & $01 / 09 / 2007$ & 12 \\
2 & $1,295,456.00$ & $1,269.01$ & $01 / 11 / 2007$ & 14 \\
3 & $1,138,143.00$ & $1,478.55$ & $01 / 03 / 2007$ & 9 \\
4 & $1,213,696.50$ & $1,408.25$ & & \\
5 & $978,031.00$ & $1,647.93$ & & \\
\hline
\end{tabular}

\section{CONCLUSION}

Based on the result, the following conclusions were made:

- The prime scheme is carried out using scenario 1 (single injector A-41BWAT), which is based on the oil cumulative as well as a consideration related to minimizing operational cost.

- Both injections through A-41BWAT and A-41 demonstrate the best result, unfortunately, an intersection occurred on September 1, 2007, 12 months after the kick-off.

- The intersecting water flow leads to excess water flow in the pathlines and delivers an early breakthrough.

\section{Acknowledgments}

This research is supported by Directory of Research and Community Service of the Universitas Islam Riau (UIR) under the grant number 374/KONTRAK/LPPM-UIR/4-2018. The authors are grateful to the Department of Petroleum Engineering of UIR for their technical support. The authors are also grateful to the Study Centre of Energy, Data Science, and Numerical Simulation to collaborate and cooperate.

\section{References}

Alhuthali, A., Oyerinde, A., \& Datta-Gupta, A. (2007). Optimal Waterflood Management Using Rate Control. SPE Reservoir Evaluation \& Engineering, 10(05), 539-551. https://doi.org/10.2118/102478-PA

Anisimov, L. (2009). The Use of Tracers for Reservoir Characterization. The SPE Middle East Oil and Gas Show and Conference, 1(March), 128-135. https://doi.org/10.2118/118862-MS

Asadollahi, M. (2012). Waterflooding Optimization for Improved Reservoir Management (Issue March). Norwegian University of Science and Technology.

Bale, A., Fossen, H., Berg, E., Mjelde, Ø., \& Kui, T. (2008). Comprehensive mini-frac testing in the gullfaks field as a tool for characterization of reservoir structure and rock mechanics. International Petroleum Technology Conference, IPTC 2008, 1, 432-449. https://doi.org/10.3997/2214-4609pdb.148.iptc11968

Cheng, H., Shook, G. M., Taimur, M., Dwarakanath, V., Smith, B. R., Muhammad, S., Masduki, A., Mario, C. C., \& Putra, K. A. (2011). Interwell Tracer Tests to Optimize Operating Conditions for a Surfactant Field Trial: Design, Evaluation and Implications. The SPE Enhanced Oil Recovery Conference, 2(April), 11851202. https://doi.org/10.2118/144899-MS

Cuauro, A., Frans, F., Knowles, D., Wigley, P., Jevanord, K., \& Al-Sadah, A. B. (2014). Design, implementation and results of an inter-well chemical water tracers pilot test to improve water flood in complex reservoirs. International Petroleum Technology Conference 2014, IPTC 2014: Unlocking Energy Through Innovation, Technology and Capability, 5, 3990-3998. https://doi.org/10.3997/2214-4609pdb.395.iptc-17682-ms

Du, Y., \& Guan, L. (2005). Interwell tracer tests: Lessons learned from past field studies. SPE Asia Pacific Oil and Gas Conference and Exhibition - Proceedings, 211-219. https://doi.org/10.2523/93140-ms

Flo, P. I. B., Hersandi, S. R., Karam, T., Shevchenko, E., \& Zhang, R. (2012). Gullfaks Village.

Guan, L., \& Du, Y. (2004). Case study on interwell gas tracer modelling. Canadian International Petroleum 
Conference 2004, CIPC 2004, 1-5. https://doi.org/10.2118/2004-189

Hesjedal, A. (Statoil), \& Eltvik, P. (Statoil). (2008). Introduction to the Gullfaks Field. http://www.ipt.ntnu.no/\%7B \%7Dtpg5200/intro/gullfaks\%7B_\%7Dintroduksjon.html

Huseby, O., Hartvig, S., Jevanord, K., \& Dugstad, Ø. (2015). Tracer technologies to assess and monitor EOR and IOR projects. http://mediasite.uis.no/Mediasite/Play/c3907715cacb4241913365518a6944b31d?catalog=6f1b9c 70-dea0-4c1b-a7b3-90a27f003ad3

Huseby, O., Hartvig, S. K., Jevanord, K., Viig, S. O., \& Dugstad, Ø. (2014). High quality flow information from tracer data. Society of Petroleum Engineers - SPE Bergen One Day Seminar 2014, 2 April, 2014, 28-36. https://doi.org/10.2118/169183-ms

Martha, C., Frode, B., Kyrre, B., Paul, C., \& Rudi, O. (2000). A Fully Compositional Streamline Simulator. Proceedings of SPE Annual Technical Conference and Exhibition, 1, 1-10. https://doi.org/10.2523/63156-MS

Melo, M. A., \& Almeida, A. R. (2017). Determining the sweep efficiency of waterflooding using tracers. Society of Petroleum Engineers - SPE Latin America and Caribbean Mature Fields Symposium 2017, c(March 2017), 15-16. https://doi.org/10.2118/184956-ms

Mursyidah, Putra, D., \& Futur, L. (2020). Re-design waterflood pattern by utilizing the tracers test technique and interwell streamline simulator. AIP Conference Proceedings, 2230, 030004. https://doi.org/10.1063/5.0002736

Nordas, H. K. (2000). Gullfaks -The First Norwegian Oil Field Developed and Operated By Norwegian Companies. In CMI Working Papers.

Park, C., Kang, J. M., Jung, Y., \& Kim, S. (2006). Streamline-based simulation to investigate interwell connectivity and tracer transport in 3D discrete fractured reservoir. 68th European Association of Geoscientists and Engineers Conference and Exhibition, Incorporating SPE EUROPEC 2006, EAGE 2006: Opportunities in Mature Areas, 5, 2787-2796. https://doi.org/10.2118/100216-ms

Putra, D. F. (2007). CO2 Injection in an Oil Reservoir with Gas Cap (Compositional Simulation Case at Gullfaks Field Norway) (Vol. 3, Issue 2). Norwegian University of Science and Technology.

Ruan, F., Carhart, S., Giordano, R. M., Grinestaff, G. H., Bratvedt, F., \& Olufsen, R. (2002). An Overview of Streamline Tracer Modeling of Miscible/Immiscible WAG Injection IOR. Proceedings of SPE/DOE Improved Oil Recovery Symposium, 672-680. https://doi.org/10.2523/75198-MS

Sagen, J., Cvetkovic, B., Brendsdal, E., Halvorsen, G., You, Y. L., \& Bjornstad, T. (1996). Reservoir ChemicalThermal Simulation with Tracers. European Petroleum Conference, 2, 427-439. https://doi.org/10.2118/36921-MS

Samaniego, F., Pulido, H., Rivera, J., Camacho Velazquez, R., Perez Olave, V. H., \& Martinez, B. (2005). A Tracer Injection-Test Approach to Reservoir Characterization: Theory and Practice. The International Petroleum Technology Conference, 1849-1861. https://doi.org/10.2523/IPTC-11038-MS

Sanni, M. L., Al-Abbad, M. A., Kokal, S. L., Hartvig, S., Olaf, H., \& Jevanord, K. (2015). A field case study of interwell chemical tracer test. Proceedings - SPE International Symposium on Oilfield Chemistry, 2(Zemel 1995), 753-769. https://doi.org/10.2118/173760-ms

Talukdar, S., \& Instefjord, R. (2008). Reservoir Management of the Gullfaks Main Field. The Europec/EAGE Conference and Exhibition, June 2008, 9-12. https://doi.org/10.2118/113260-MS

Temizel, C., Putra, D., Alklih, M. Y., Najy, A. K., Jia, B., \& Yang, G. (2018). Modeling and Simulation of Smart Gels for Conformance Improvement in Waterflooding. The SPE Improved Oil Recovery Conference, 2018-April. https://doi.org/10.2118/190275-MS

Thrasher, D., Nottingham, D., Stechauner, B., Ohms, D., Stechauner, G., Singh, P. K., \& Lara Angarita, M. (2016). Waterflood sweep improvement at Prudhoe Bay, Alaska. SPE - DOE Improved Oil Recovery Symposium Proceedings, 2016-Janua.

Viig, S. O., Juilla, H., Renouf, P., Kleven, R., Krognes, B., Dugstad, Ø. ., \& Huseby, O. K. (2013, April 8). Application of a New Class of Chemical Tracers to Measure Oil Saturation in Partitioning Interwell Tracer Tests. The SPE International Symposium on Oilfield Chemistry. https://doi.org/10.2118/164059-MS 
Zemel, B. (1995). Tracers in the oil field. Elsevier Science B.V. 